Article

\title{
Retention of Contaminants Elements from Tailings from Lead Mine Washing Plants in Ceramics for Bricks
}

\author{
Jorge Suárez-Macías * $\mathbb{D}$, Juan María Terrones-Saeta $\mathbb{D}$, Francisco Javier Iglesias-Godino $\mathbb{D}$ \\ and Francisco Antonio Corpas-Iglesias
}

Department of Chemical, Environmental, and Materials Engineering, Higher Polytechnic School of Linares, University of Jaen, Scientific and Technological Campus of Linares, 23700 Linares, Spain;

terrones@ujaen.es (J.M.T.-S.); figodino@ujaen.es (F.J.I.-G.); facorpas@ujaen.es (F.A.C.-I.)

* Correspondence: jsuarez@ujaen.es; Tel.: +34-635-053-501

Received: 7 June 2020; Accepted: 24 June 2020; Published: 26 June 2020

check for updates

\begin{abstract}
Mining activity is essential for the social welfare of the population. However, this activity produces a series of mining waste. These mining wastes, if not properly treated, can produce significant environmental pollution. This study develops the incorporation of tailings from washing plants in ceramic materials for bricks in order to retain the contaminating elements in the ceramic matrix. To this end, firstly, a physical and chemical characterisation of the mining waste is carried out and different groups of samples are conformed with clay and mining waste. These conformed samples with mining waste are evaluated through different physical and mechanical tests typical in the ceramic industry, studying the variation of properties by the incorporation of the waste. In turn, the leachates from the groups of conformed samples are analyzed, confirming the retention of the contaminating elements of the mining waste in the ceramic matrix. The results of these tests showed that ceramics can be made for bricks with up to $90 \%$ mining waste, obtaining physical and mechanical properties acceptable regarding the regulations and retaining the contaminating elements in the ceramic matrix, as confirmed by the leachate tests.
\end{abstract}

Keywords: ceramics; bricks; mining waste; tailings; clay; leachate; sustainability; circular mining; compressive strength

\section{Introduction}

The mining sector is essential for the development, economy, and well-being of the population, since all the materials we currently use derive or have derived of these. However, it is also important to note that it is one of the sectors that causes the most pollution and environmental impact. Therefore, there are currently stricter environmental regulations than in previous times and that, in some cases, makes the extraction of useful minerals for the industry unviable. However, a prohibition of the extraction of materials by mining techniques is not the right trend, but rather a global study of the mine in order to produce the least waste affecting the environment. That is to say, an integral study cycle particularized for each mine, in which the waste produced is observed on the basis of the defined extraction methods what are the wastes produced, the production processes are optimized and these wastes are analyzed as new raw materials for other industrial processes. Always with the unquestionable adequacy of the land once the mining operations have been completed.

Based on the above, there are different wastes or residues from mining operations of minerals. Among them, and common in the extraction of metallic elements, are the tailings from flotation or gravimetric processes, to a lesser extent the latter at present. These tailings from washing plants 
from flotation or gravimetric processes are very common in mining processing for later subjecting the concentrated mineral to pyrometallurgical, and to a lesser extent, hydrometallurgical processes [1,2]. These tailings have a very different chemical composition depending on the rock or mineral from which they come, containing a large number of heavy metals when the mine is for the extraction of metallic elements. This occurs because, in the processes of concentration in the washing plants, by flotation or by gravimetry, only the desired metallic element is concentrated, leaving the rest of the metallic elements in the waste in a smaller proportion. In turn, it should be remembered that the metallic elements in the minerals and rocks do not appear alone in most cases, so the existence of, for example, Copper Sulphides, normally involves the existence of a smaller proportion of Iron Sulphides, Zinc Sulphides, Barium Sulphides, Arsenic Sulphides, etc. These minerals exist in the deposits of the mining waste after the concentration of the main element. In addition, there are millions of tons of tailings from washing plants processed during decades of mining activity in the same mine [3,4]. These mining wastes are usually deposited in the proximity of the plant to, at best, be waterproofed and form landfills. In other cases, depending on the existing regulations in each country and the evolution of these regulations, these wastes have been uncontrollably thrown around the treatment plant.

As has been mentioned, these tailings from a washing plant or concentration plants have, in the case of mining for the extraction of metal elements, a large percentage of heavy metals in smaller proportions. At the same time, the flotation or gravimetric process forces the particle size to be considerably small so that the processes are carried out correctly. Therefore, it is necessary to think about the negative influence that this mining waste will create in the environment due to its chemical composition and grading.

This mining waste in contact with storm water or river water, as well as its dispersion by the wind due to its reduced particle size, causes the contamination of surface and/or ground water, the affection of the ecosystem and a risk for living beings, fauna and even people [5,6]. In addition, arid or semi-arid areas with reduced vegetation condition greater pollution due to the dispersion of particles with the wind, since there is no vegetation that retains these residues [7]. However, it is not common for vegetation to develop in the deposits of tailing from washing plants, as the presence of heavy metals has a significant influence on the flora [8-10]. They are therefore large deposits of mining waste that change over time by various processes of erosion with associated pollution, destroying the landscape of the area [11-13].

The existence in previous times of less restrictive environmental regulations makes the situation even more alarming, as is the case of the area of study of this work. The large amounts disposed of tailings from washing plants outdoors, without waterproofing and without subsequent adequacy work to prevent contamination, is a serious environmental problem. In addition, in most cases, they were located in places that are inadmissible and unthinkable at present, such as near rivers, lakes, tributaries, etc. $[14,15]$. This fact poses a problem, not only for the fauna and flora, but also for the public health of the residences near the deposition area, as in the case study [16].

In order to avoid the deposition of these mining wastes, as well as to provide a new use for them within the framework of the circular economy, different researches have been developed in this respect. One of the options is the extraction of those elements that are found in the waste because they were not of interest in the labors of primary mining $[17,18]$. These metallic elements are found in low proportion and combined with other minerals, so their extraction by pyrometallurgical methods is unfeasible in most cases $[19,20]$. However, the new techniques developed in hydrometallurgy, some at atmospheric pressure and ambient temperature, have very low extraction costs, so the recovery of these elements can be viable [21]. The lower grade of the mineral is compensated by the more economical processes of processing and the lower costs of the raw material, with the extraction of the elements by hydrometallurgy being interesting as different investigations have shown.

On the other hand, there are tailings from washing plants that have a very low proportion of metal elements of interest that cannot be treated, since they would make even hydrometallurgical techniques 
unviable. In turn, hydrometallurgical techniques also produce waste after the leaching of elements that cannot be deposited freely, so it is necessary to develop new uses for these mining wastes.

Based on the above, different lines have been developed in which this mining waste was used as a raw material for other materials. The new product must be capable of retaining and accepting the mining waste in order for viability to take of the project, as well as lessening environmental pollution. Among the materials in which the tailings from mining washing plants have been incorporated are mainly cement [22], and consequently mortar and concrete [23]. In the investigations developed in this line, its incorporation has been evaluated as well as the effect on the finished material, determining in most cases a decrease in resistance. It is important that the final material retains the elements adequately and supports the possible variations in the chemical composition of the waste over time, so it may be thought that cement is not the best material for incorporation. Mainly, because of the influence in the setting processes and the acquisition of the resistance of the Sulfur, Chlorine, organic matter, etc. There are also isolated cases in which even membranes have been developed with these wastes or porous materials [24]. However, research into the reuse of these wastes in other materials is still necessary.

It should be noted that the materials used for the incorporation of the tailings from washing plants are mostly construction materials. This is due to the fact that the construction sector is one of the most demanding sectors in terms of raw materials, expertly extracted from different mines and in high proportions [25]. At the same time, it is one of the most polluting sectors [26], so different lines have been developed to reduce the consumption of raw materials with the incorporation of waste [27-30], thus creating more sustainable materials for construction.

In the present study, and based on what has been previously commented, the incorporation of tailings from washing plants by gravimetric techniques into ceramic materials for bricks is detailed, using this waste as raw material and avoiding the environmental pollution caused. These mining wastes come from the area of Linares, Spain, and belong to the lead mines that were established in the middle of the 19th century. The environmental regulations in this respect did not include sufficient measures to prevent the contamination of ground water and surface water, as well as flora and fauna, causing significant pollution in the ecosystem [31].

The choice of ceramics for bricks as the main material for the incorporation of the waste is motivated by different reasons that are detailed below.

- The manufacturing of bricks with red clay is an industrial activity developed and near to the location of the gravimetric tailings.

- This industry consumes large quantities of raw materials, clay, for obtaining the brick as a final product.

- There are different successful cases in which waste has been incorporated as a substitute for the raw material for bricks manufacture [32-35], obtaining ceramic materials with suitable properties according to European regulations and with very interesting particular characteristics [36].

- For their incorporation, it is not necessary to make great changes in the manufacturing process [37].

- It avoids the extraction of new raw materials such as clay, with the consequent reduction of greenhouse gases and environmental impact [38,39].

- This incorporation of mining waste in ceramics for bricks eliminates the deposition of tailings and consequently the effect on the environment.

- The ceramic matrix is capable of retaining most of the heavy metals present in the mining waste, preventing its subsequent leaching and pollution [40].

This is therefore a study that develops in depth the reuse of a highly polluting mining waste, which produces a material with good characteristics for commercialization and which creates a sustainable material.

In order to achieve the final objective of this work, a series of logically ordered phases were carried out that were able to objectively evaluate the viability of the incorporation of tailings from mining 
washing plants in the ceramic for bricks. Firstly, the physical properties and chemical composition of the clay and mining waste were analysed. In this way, the compatibility between materials was evaluated as well as the elements or chemical compounds of the waste to which more attention should be paid for its use. Subsequently, samples were conformed and sintered with different combinations of the materials under study, clay and tailings from washing plants, from $100 \%$ clay to $100 \%$ mining waste. These samples were evaluated by different physical and mechanical tests in order to determine the influence of the waste on the final material. Finally, leachate tests were carried out to analyze in detail the retention of the chemical contaminating elements present in the mining waste and thus avoid possible environmental contamination.

The tests showed, first of all, an aptitude of the red clay for use in ceramics, as well as a compatibility with the mining waste. The mining waste, tailing from the washing plant, reflected a chemical composition with different heavy metals that can indeed cause a significant environmental effect if not treated properly. The different groups of ceramic samples with different percentages of combination of both materials showed a lower density and strength with the increase of the percentage of mining waste. In turn, this lower density implies a higher porosity and lower density, these characteristics being particularly interesting. The lixiviate test of the different most conflicting chemical elements showed an important retention of them in the ceramic matrix, being in all cases the lixiviates of the ceramic materials conformed acceptable by the regulations on this respect. The maximum percentage of incorporation of tailings from mining washing plants was $90 \%$ with acceptable results. This percentage is excellent considering the advantages of the application of mining waste in ceramic materials and the reduction of the deposits of the tailings.

\section{Materials and Methods}

This section describes the materials used in the study, as well as the methodology followed. The methodology for the incorporation of mining waste in ceramics for bricks is comprised of a series of logical and ordered tests capable of objectively evaluating the end of the study. The sections mentioned below are detailed in detail.

\subsection{Materials}

The materials used in the present study are essentially clay and mining waste coming from mine washing plant tailings. These wastes are analysed in detail in the methodology, for the evaluation of their physical properties and their chemical composition. However, their location, formation and general characteristics will be described in this section in order to understand the environmental problem they supposed.

It should be noted that the mining waste used and the clay have been taken in representative samples. Therefore, the physical-chemical properties and even the particle size correspond more to a greater extent to the globality of the material.

The materials in the study have been dried for $24 \mathrm{~h}$ at a temperature of $105 \pm 2{ }^{\circ} \mathrm{C}$ to eliminate humidity. This process has been carried out to eliminate useless variables that could damage the study and cause disparity in the results. However, the existence of humidity in industry does not harm the process or the final material, it should simply be taken into account so as not to add excess water in the conforming process and to adjust to the optimal combination of materials defined in this work.

The materials used are detailed below.

\subsubsection{Clay}

The clay used in this work corresponds to the area of Linares, Spain. This clay, of remarkable quality, has been and is widely used by the ceramic industry for the manufacture of bricks. Brick manufacturing industry is common in the area and represents an important economic contribution, being a demanding activity in terms of raw materials. 
The clay presents acceptable characteristics, although these characteristics will be corroborated by the tests of the methodology. Its small particle size and chemical composition make this material very suitable for use in ceramic materials for bricks.

The clay directly received from the production industry was dried and sieved by the $0.25-\mathrm{mm}$ sieve to facilitate the mixing and homogenisation processes.

\subsubsection{Mining Waste}

The mining waste detailed and scope of this study comes from the city of Linares, in the area of Andalusia, Spain. In this area there was an important Lead extraction mining industry during the second half of the 19th century and the 20th century. It is therefore usual to find different residues, constructions, and wells from the previous mining period. This mining industry stopped its production mainly due to the low price of Lead, the main element of extraction, and the absence of studies of new exploitable seams.

More specifically, the mining waste belongs to the seam called "SAN ROQUE". This seam from which Lead was extracted through the galena mineral, Lead Sulphide, was embedded into granitic formations. Its longitude was about one kilometer and it was associated with other nearby and parallel seams to it. The existing Lead Sulphide belonged to hydrothermal processes in which a smaller proportion of Iron Sulphide, Zinc Sulphide, Barium Sulphide, Arsenic Sulphide, etc. had been produced. This mine was exploited underground from approximately 1850 to 1950, focusing its activity mainly on the 19th century.

The extracted materials were crushed and concentrated using gravimetric techniques. In turn, the finer materials obtained were processed in washing plants by gravimetric techniques, not being usual at that time the use of flotation processes. These plants extracted the Lead mineral for the subsequent pyrometallurgical processes, depositing the wastes from the washing plant near the mine.

At present, these tailings represent large waste deposits in the outdoors, without any type of waterproofing or control to avoid affecting the water, fauna, vegetation or public health. These tailings are easily recognisable, since given their chemical composition there is no vegetation in them. In addition, they are found near residential areas that have been affected by their deposit, mainly due to contamination of water wells.

The sample was taken at a depth of $2 \mathrm{~m}$ to avoid taking the most affected surface part. In turn, a total of 10 samples were taken from different areas of the tailings deposit in an attempt to take representative samples. These samples have the same particle sizes as the tailings, and no grading fraction has been altered. The mining waste will be analyzed chemically and physically, these tests are mentioned in the methodology.

\subsection{Methodology}

The methodology of this study comprises a series of logical and ordered tests for the corroboration of the final hypothesis. This hypothesis is the viability of incorporating of mining waste from Lead mine washing plants in ceramics for brick manufacture.

For this purpose, firstly, an evaluation of the physical properties of the mining waste and the clay is carried out. The chemical composition is essential to know by several factors, among these factors is the detection of elements or chemical compounds that directly damage the end ceramic, as well as the detection of possible chemical elements that could cause environmental pollution if they are not properly evaluated.

After analyzing the chemical composition, different groups of samples or families proceed to the conformation and are sintered. These families have different combinations of clay and mining waste, from $100 \%$ clay to $100 \%$ mining waste. The different groups of samples after the sintering process are characterized for the determination of the essential physical properties in ceramic materials. The compressive strength tests are essential to evaluate the maximum percentage of incorporation of the mining waste into the ceramic, since they show a minimum resistance that the final product must 
have. In turn, the colour of the different families was analysed to objectively determine their aesthetic quality, and this test is very important in the ceramic industry.

Finally, the objective is not only to provide a new life for the mining waste but also to avoid the pollution that it is currently causing. To this end, leachate tests were carried out comparing the concentration of the chemical element contaminants in the different families of ceramics conformed with the unaltered sample of the mining waste.

The logical order of the methodology will be able to detect those points of conflict, as well as the weaknesses and fortresses of the study. In the following sections, we proceed the above-mentioned tests are described in more detail, divided into three big blocks: analysis of the initial materials, conformation of the samples and tests, and finally, evaluation of the leachates of the ceramics.

\subsubsection{Analysis of the Initial Materials}

Firstly, and as an essential point of this study, the physical and chemical characterization of the waste was carried out. In turn, the clay was studied to evaluate the compatibility between both materials. This characterisation is essential to predict the behaviour of the final ceramic created and its properties, detecting those characteristics that may be harmful and controlling them during the conforming process.

First, the physical properties were analysed. Among these properties, the density of the clay particles and the mining waste was studied according to the standard UNE-EN 1097-7, using the pycnometer method. The particle density of the materials is essential to evaluate the compatibility between materials. If the density between both materials differs in great proportion it could cause problems in the mixture, creating separation between them. In turn, a very different density would require the use of volumetric corrections of all the parameters that influence the study. To calculate the density of the particles, a series of weight and volume measurements are made with the pycnometer as the main instrument and water of known density at a given temperature.

The main idea is the incorporation of the mining waste without the need for any previous treatment, so the particle size must be analyzed to corroborate that a ceramic with good physical properties and resistance will be created. A big particle size of mining waste would cause the need for a grinding process to be carried out for use in ceramics, with the consequent associated industrial cost. This test was carried out according to the standard UNE-EN 933-1.

The chemical composition has a significant influence on the environmental pollution of the waste, as well as on the quality of the final manufactured material. Therefore, a thorough analysis of the chemical composition of the mining waste and the clay is necessary to evaluate those chemical elements or compounds that may be critical for the manufacture of ceramics for bricks. Among the tests carried out is that of elemental analysis. This test determines the percentage of Carbon, Nitrogen, Hydrogen and Sulfur present in the material. For this purpose, the sample is combusted at a temperature of $1000 \pm 5^{\circ} \mathrm{C}$ and the combustion gases are analyzed. This test was performed with the TruSpec Micro equipment of the LECO brand. The loss on ignition represents the loss of mass of the sample after being subjected to a temperature of $1000 \pm 5^{\circ} \mathrm{C}$. Both tests are related and obtain complete values of the detailed chemical elements.

In X-ray fluorescence analysis with the ADVANT'XP+ equipment (Thermo Fisher Scientific, Waltham, MA, USA) of the Thermo Fisher brand, the percentage in which the different chemical elements in the sample are present is determined. This test reflected those potentially contaminating chemical elements and the percentage in which they were found. These elements were later analyzed with leaching tests of the ceramics obtained, evaluating their retention in the ceramic matrix. It must be taken into account that the X-ray fluorescence equipment analyzes the chemical elements with the highest atomic weight. Therefore, the sample must be calcined to eliminate those elements that it does not evaluate and divide the percentages of the composition in a balanced way among the detected elements. Otherwise, there would be a higher proportion of chemical elements detected by this test 
method, as it would hide the lower atomic weight elements. This calcination process is for X-ray fluorescence testing and it is not presented again in the methodology.

\subsubsection{Conformation of the Samples and Tests}

Once the starting materials had been analysed, as well as the compatibility between them, the different groups of samples or families were manufactured. These sample groups contain different percentages of clay and mining waste, tailings from Lead mine washing plants. In order to cover the greatest number of possible combinations and to study the effect of the ceramic obtained with the percentage of mining waste, families were conformed from $100 \%$ clay to $100 \%$ mining waste. The mining waste percentage was progressively increased in percentage increments of $10 \%$. The names of the different groups of samples, as well as the percentage of clay and mining waste they contain, can be seen in Table 1.

Table 1. Conformed ceramics families with combined percentages of clay and mining waste.

\begin{tabular}{ccc}
\hline Samples Groups & Clay, (\%) & Mining Waste, $(\mathbf{\%})$ \\
\hline 0M10C & 100 & 0 \\
1M9C & 90 & 10 \\
2M8C & 80 & 20 \\
3M7C & 70 & 30 \\
4M6C & 60 & 40 \\
5M5C & 50 & 50 \\
6M4C & 40 & 60 \\
7M3C & 30 & 70 \\
8M2C & 20 & 80 \\
9M1C & 10 & 90 \\
10M0C & 0 & 100 \\
\hline
\end{tabular}

The existence of the $0 \mathrm{M} 10 \mathrm{C}$ family is useful to be able to compare the results of the ceramics obtained with the mining waste and the traditional ceramic without additions. Something similar occurs with the 10M0C family conformed only with mining residue and in order to determine the extreme properties of the possible combinations. In this way it is possible to evaluate accurately and objectively the influence that the mining residue has on the final ceramic and its properties.

Once the combinations of materials for the different groups of samples were determined, the different samples of each family were conformed, with a total of 15 samples for each family. The samples were first mixed and homogenized in the appropriate proportion. Subsequently, $10 \%$ water was added to the total mass of clay and mining waste. This percentage of water was evaluated as optimal for the conforming process. Higher percentages created water exudation during compaction, while lower percentages of water caused lower density of the specimens due to less compaction.

The mixture of both materials, clay and mining waste, and the water are poured into the metal matrix and then, by means of a rammer, a pressure of $50 \pm 1 \mathrm{MPa}$ is applied. The conforming process is the same for all the samples with the same speed of compaction and the same maximum pressure of $50 \pm 1 \mathrm{MPa}$, for this a Testing Machines model AG-300kNX of the brand Shimadzu was used. The metal matrix used has internal dimensions of $60 \mathrm{~mm}$ long and $30 \mathrm{~mm}$ wide, so these will be the approximate dimensions of the samples obtained.

Once the samples are conformed, they are extracted and dried for $24 \mathrm{~h}$ at a temperature of $105 \pm 2{ }^{\circ} \mathrm{C}$. This process is carried out to eliminate the water present in the sample in a progressive process and not abrupt process, avoiding the creation of cracks in the material. After, the dried samples are then measured and weighed for it test. Sintering is carried out in the muffle furnace at a temperature of $950 \pm 5{ }^{\circ} \mathrm{C}$ for one hour, for which the temperature is raised at a rate of $4{ }^{\circ} \mathrm{C}$ per minute from ambient temperature to sintering temperature. The same applies to cooling, using the same speed. 
The sintered samples are weighed and measured again for the various physical and mechanical tests. The physical tests carried out are the determination of weight loss, determination of linear shrinkage (UNE-EN 772-16 standard), capillary water absorption (UNE-EN 772-11 standard), cold-water absorption (UNE-EN 772-21 standard), bulk density, and open porosity (UNE-EN 772-4 standard).

The weight loss and linear shrinkage test calculates the differences in mass and dimensions in the samples after sintering. These simple tests reflect the behaviour of the ceramic beforehand, as they have a significant influence on the subsequent characteristics. In turn, capillary water absorption represents the variation of the mass of a sample when it is partially submerged for 1 minute in water, thus reflecting the quality of the structure of the ceramic and the pores that are connected. Associated with this test is the cold-water absorption test, determining the variation of the mass of the specimens with immersion for $24 \mathrm{~h}$ in water at ambient temperature. This test is essential for ceramic elements that are outdoors, since it reflects the water absorption and the greater weight that the ceramic element will have on the structure. Finally, the open porosity and bulk density tests were carried out with different measurements of the mass of the samples in dry, after immersion in water and submerged in water. With these data, we obtained the results through different equations detailed in the standard on the subject.

One of the essential tests in ceramics for bricks is the compressive strength test. This test was carried out according to the standard UNE-EN 772-1 with the Testing Machine model AG-300kNX of the brand Shimadzu. It was performed with the standardized speed of load application and automatic detection of maximum resistance. The compressive strength test determines those families of samples that do not obtain acceptable results for use and are therefore rejected. This limitation is established by the European regulations, setting a minimum compressive strength of $10 \mathrm{MPa}$.

Finally, the color was objectively measured for all families of samples. An instrument called a colorimeter (model RGB-2 of the trademark PCE, PCE Instruments, Southampton, UK) was used for this purpose. This equipment determines the color coordinates of the samples according to the primary colors Red, Green and Blue, quantifying it to be easily reproducible by graphic means. It must be taken into account that colour is one more characteristic of the ceramic material, which is not limited by the standards and is limited by the intense quality controls of the ceramic industry. It is therefore a characteristic that should not be underestimated.

\subsubsection{Evaluation of the Leachates of the Ceramics}

One of the main objectives of this study was the retention of those contaminating elements that are present in the mining waste from tailings from mining washing plants. These mining wastes are currently causing significant environmental pollution, so that the material incorporating them must avoid that be production of polluting leachate. In order to evaluate this characteristic leachate tests were carried out on all sample families with acceptable results. In the analysis of the leachates, the concentration of the most contaminating elements and in greater proportion existing in the sample was evaluated. To confirm the retention of these chemical elements, the results of the leachates of the families were compared with the leachates of the unaltered mining waste sample, thus being able to quantify the retention.

The test was carried out in accordance with the standard for this purpose UNE-EN 772-5, which describes a leaching process detailed below:

- The dry and crushed sample to be leached is taken, weighing about $20 \pm 0.05 \mathrm{~g}$.

- Then, it is poured into a polyethylene bottle with $200 \mathrm{~mL}$ of deionized water.

- Then it is shaken for $60 \pm 2 \mathrm{~min}$ by means of a horizontal shaker at $120 \pm 5 \mathrm{~min}^{-1}$ with a horizontal movement of $20 \mathrm{~mm}$ and ambient temperature.

- After $15 \pm 1 \mathrm{~min}$ from the completion of the extraction, the in suspended sample is filtered through with ash-free blue band paper filter and the filtrate is collected in a clean flask. 
Leachate samples from all ceramic families that be conformed with acceptable results and from the mining residue sample were analyzed with Inductively Coupled Plasma-Mass Spectrometry. The ICP-MS used was the Agilent 7900 (Agilent Technologies, Santa Clara, CA, USA). With this equipment it is possible to determine the concentration of the chemical elements present in the mining waste in a quantitative way, since standards were used during the test. The results reflected the retention of the chemical elements, as well as the feasibility of manufacturing the ceramic families by comparing the results with the maximums established by the standards.

\section{Results and Discussions}

Next the results of the different tests detailed in the methodology are described. These results provide a series of partial conclusions that will define the final conclusion. The final conclusion of this study is the assessment of the feasibility of incorporating mining waste from Lead mine washing plants, in ceramics for bricks. The results are shown below in the three main blocks discussed.

\subsection{Analysis of the Initial Materials}

The analysis of the physical and chemical characteristics of the materials reflects the compatibility between them, as well as the existence of some chemical elements pollutants that can cause environmental pollution if not controlled.

The first of the physical tests carried out was that of particle density. The clay showed a density of $2.44 \pm 0.04 \mathrm{~g} / \mathrm{cm}^{3}$, being this value usual in clayey materials. On the other hand, the mining waste reflected a density of $2.86 \pm 0.06 \mathrm{~g} / \mathrm{cm}^{3}$, this density being slightly higher than that of the clay and provided by the heavy metals it contains. However, the densities of both materials are relatively similar so they should not cause problems in the conformed of the pieces, nor are volumetric corrections necessary.

On the other hand, it should be remembered that the clay was sieved for use by the $0.25 \mathrm{~mm}$ sieve. This clay has a very small particle size due to its origin and formation, so the particle size of the mining waste was studied to evaluate its direct incorporation. The grading curve of the mining waste is detailed in Figure 1.

GRADING CURVE OF MINING WASTE

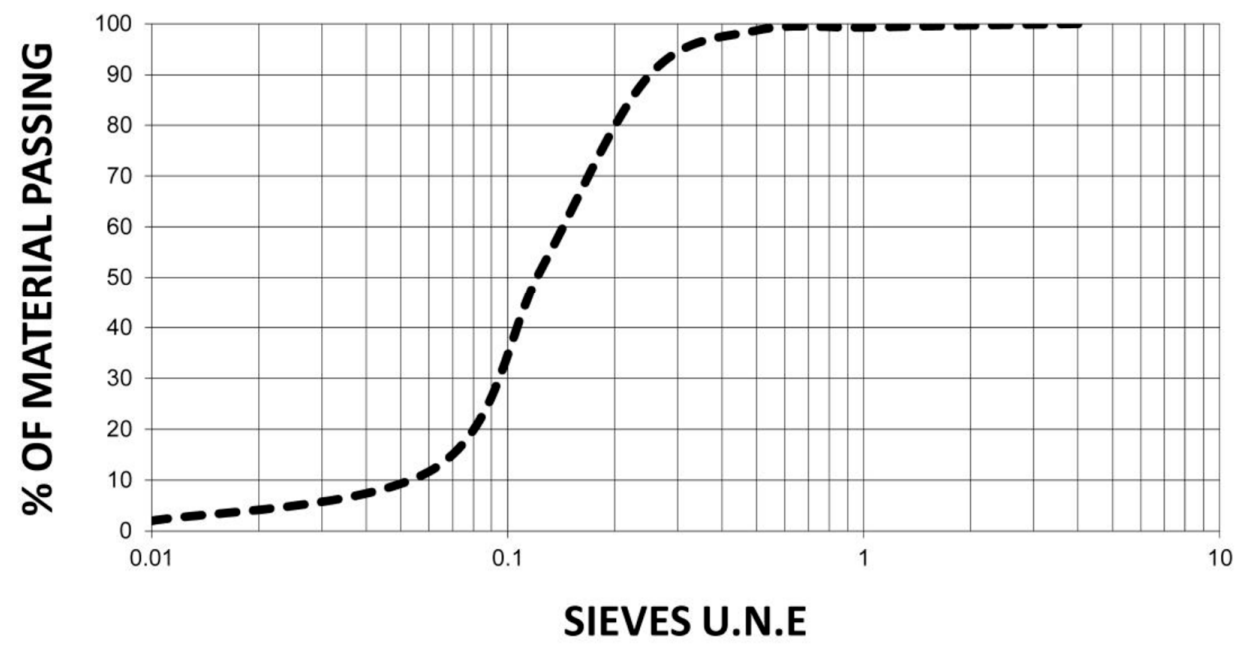

Figure 1. Grading curve of mining waste coming from tailings from washing plants.

Figure 1 reflects how the particle sizes of the mine waste are mostly less than $0.3 \mathrm{~mm}$, so compatibility with the clay screened by the $0.25 \mathrm{~mm}$ sieve is optimal. This reduced particle size of the mine waste directly benefits the ceramics materials conformed process, however, its deposition in the 
outdoors has created a significant contamination by its dragging with the wind and the different types of erosion.

Once the essential physical properties have been analysed, be proceed carried out the chemical tests. Firstly, the elemental analysis test was carried out for the clay and mining waste. This test quantifies the proportion of the chemical elements Carbon, Nitrogen, Hydrogen, and Sulfur when the sample is combusted at the temperature of $1000 \pm 5^{\circ} \mathrm{C}$. The results of the elemental analysis test are given in Table 2.

Table 2. Elemental analysis Carbon, Hydrogen, Nitrogen and Sulfur for clay and mining waste.

\begin{tabular}{ccccc}
\hline Samples & Nitrogen, (\%) & Carbon, (\%) & Hydrogen, (\%) & Sulfur, (\%) \\
\hline Clay & $0.04 \pm 0.00$ & $1.16 \pm 0.05$ & $0.65 \pm 0.02$ & $0.00 \pm 0.00$ \\
Mining waste & $0.00 \pm 0.00$ & $3.57 \pm 0.07$ & $0.16 \pm 0.00$ & $0.00 \pm 0.00$ \\
\hline
\end{tabular}

The elemental analysis of the clay reflects a low percentage of carbon, so it shows the practically absence of carbonates or organic matter in its composition. This is an essential fact that reflects the quality of clay as a raw material for ceramics. At the same time, there is a reduced percentage of Hydrogen probably produced by the hydrated compounds that the clay contains. In the case of mining waste, the percentage of Carbon is also reduced, although it is higher than in clay. However, this percentage should not cause problems in the ceramic as it most probably corresponds to a low percentage of carbonates. The hydrogen present in the sample is very low, due mainly to some hydrated compound or simply to unavoidable moisture in the sample. It is worth noting the zero Sulfur value obtained in both samples. In the clay this zero value reflects the quality of the material but in the mining residue it implies much more. The null value in the mining residue of Sulfur, starting from this metal sulphide residue, shows how the mining process carried out previously and the exposure to the elements for more than 50 years to the elements has made possible the oxidation of the elements and the inexistence of Sulfur. This is an excellent fact for the manufactured material because it will not be damaged by Sulfur but, at the same time, it reflects the contamination that has existed due to the deposit of tailings in the area.

The loss on ignition reflected the loss of mass when the samples are subjected to the temperature of $1000 \pm 5^{\circ} \mathrm{C}$. This loss of mass can be due to different factors, including the removal of organic matter, the removal of carbonates, the transformation of some chemical compounds and the oxidation of some chemical elements. The results of the loss on ignition test of the clay and mining waste are detailed in Table 3.

Table 3. Loss on ignition of clay and mining waste.

\begin{tabular}{cc}
\hline Sample & Loss on Ignition, (\%) \\
\hline Clay & $7.90 \pm 0.35$ \\
Mining waste & $11.71 \pm 0.39$ \\
\hline
\end{tabular}

The loss on ignition of clay and mining waste is very similar. This loss on ignition is mainly due to the transformation of some chemical compounds and the oxidation of other chemical elements, since as was previously determined by elemental analysis, the percentage of Carbon is very low. Both values are acceptable and will reflect very similar mass loss results in the samples.

X-ray fluorescence provides the elemental composition of the samples, detailing those elements with the highest atomic weight. Among these chemical elements are all the heavy metals that are a source of contamination by the waste. X-ray fluorescence test results for clay and mining waste are detailed in Table 4. 
Table 4. X-ray fluorescence of the clay and minng waste samples.

\begin{tabular}{|c|c|c|}
\hline Compound & Clay, wt $\%$ & Mining Waste, wt $\%$ \\
\hline $\mathrm{SiO}_{2}$ & $52.62 \pm 0.25$ & $42.71 \pm 0.22$ \\
\hline $\mathrm{Al}_{2} \mathrm{O}_{3}$ & $17.83 \pm 0.19$ & $10.79 \pm 0.14$ \\
\hline $\mathrm{Fe}_{2} \mathrm{O}_{3}$ & $7.84 \pm 0.13$ & $6.20 \pm 0.11$ \\
\hline $\mathrm{K}_{2} \mathrm{O}$ & $5.63 \pm 0.12$ & $4.33 \pm 0.09$ \\
\hline $\mathrm{MgO}$ & $3.44 \pm 0.09$ & $2.10 \pm 0.07$ \\
\hline $\mathrm{CaO}$ & $3.19 \pm 0.09$ & $18.28 \pm 0.17$ \\
\hline $\mathrm{TiO}_{2}$ & $0.769 \pm 0.038$ & $0.563 \pm 0.027$ \\
\hline $\mathrm{Na}_{2} \mathrm{O}$ & $0.165 \pm 0.015$ & $0.423 \pm 0.071$ \\
\hline $\mathrm{P}_{2} \mathrm{O}_{5}$ & $0.154 \pm 0.008$ & - \\
\hline $\mathrm{P}$ & - & $0.0975 \pm 0.0048$ \\
\hline $\mathrm{MnO}$ & $0.154 \pm 0.008$ & $0.966 \pm 0.044$ \\
\hline $\mathrm{ZrO}_{2}$ & $\begin{array}{c}0.0379 \pm \\
0.0049\end{array}$ & $0.0484 \pm 0.0024$ \\
\hline $\mathrm{V}_{2} \mathrm{O}_{5}$ & $\begin{array}{c}0.0357 \pm \\
0.0031\end{array}$ & $0.0102 \pm 0.0015$ \\
\hline $\mathrm{SrO}$ & $\begin{array}{c}0.0344 \pm \\
0.0036\end{array}$ & $0.0208 \pm 0.0010$ \\
\hline $\mathrm{RuO}_{4}$ & $\begin{array}{c}0.0318 \pm \\
0.0021\end{array}$ & - \\
\hline $\mathrm{Rb}_{2} \mathrm{O}$ & $\begin{array}{c}0.0273 \pm \\
0.0048\end{array}$ & $0.0188 \pm 0.0009$ \\
\hline $\mathrm{PdO}$ & $\begin{array}{c}0.0273 \pm \\
0.0040\end{array}$ & - \\
\hline S & $\begin{array}{c}0.0247 \pm \\
0.0013\end{array}$ & - \\
\hline $\mathrm{SO}_{3}$ & - & $0.173 \pm 0.008$ \\
\hline $\mathrm{NiO}$ & $\begin{array}{c}0.0233 \pm \\
0.0020\end{array}$ & $0.0052 \pm 0.0010$ \\
\hline $\mathrm{PtO}_{2}$ & $\begin{array}{c}0.0184 \pm \\
0.0039\end{array}$ & - \\
\hline $\mathrm{Cr}_{2} \mathrm{O}_{3}$ & $\begin{array}{c}0.0164 \pm \\
0.0023\end{array}$ & $0.0117 \pm 0.0012$ \\
\hline $\mathrm{Cl}$ & $\begin{array}{c}0.0095 \pm \\
0.0008\end{array}$ & - \\
\hline $\mathrm{Co}_{3} \mathrm{O}_{4}$ & $\begin{array}{c}0.0078 \pm \\
0.0023\end{array}$ & $0.0086 \pm 0.0010$ \\
\hline $\mathrm{MoO}_{3}$ & $\begin{array}{c}0.0063 \pm \\
0.0018\end{array}$ & - \\
\hline $\mathrm{ZnO}$ & $\begin{array}{c}0.0062 \pm \\
0.0027\end{array}$ & $0.0780 \pm 0.0039$ \\
\hline $\mathrm{As}_{2} \mathrm{O}_{3}$ & - & $0.0153 \pm 0.0024$ \\
\hline Ar & - & $0.0018 \pm 0.0007$ \\
\hline $\mathrm{CuO}$ & - & $0.108 \pm 0.005$ \\
\hline $\mathrm{Ga}_{2} \mathrm{O}_{3}$ & - & $0.0026 \pm 0.0006$ \\
\hline $\mathrm{Y}_{2} \mathrm{O}_{3}$ & - & $0.0101 \pm 0.0008$ \\
\hline $\mathrm{Sb}_{2} \mathrm{O}_{3}$ & - & $0.0029 \pm 0.0013$ \\
\hline $\mathrm{BaO}$ & - & $0.8701 \pm 0.0429$ \\
\hline $\mathrm{PbO}$ & - & $1.63 \pm 0.06$ \\
\hline
\end{tabular}

The X-ray fluorescence of the clay reflects a usual chemical composition of an aluminum silicate. High percentages of Silicon and Alumina are present due to its composition, as well as Iron Oxides, which give it the usual reddish colour of this material. Calcium and Magnesium Oxides are present in a lower proportion, being their percentage adequate for its use. Potassium, derived directly from feldspars, has a suitable percentage as it is a red clay. The other chemical elements are found in a much lower proportion and do not produce anomalies in the composition of the clay that could become a problem in the ceramic. The composition of the clay can be defined as acceptable.

On the other hand, the waste from mine tailings also has high percentages of Silica and Alumina, both of which are compounds conforming of the granite. The same happens with Calcium, an element present in feldspars that is usual in granitic rock. It should be noted that granite is the rock in which the extracted Lead seam is found, so it is common to find traces of this material in the mining waste. 
At the same time, there are percentages of Lead typical of the mining labours and derivatives of the extracted galena mineral. The existing Iron may be largely due to the metallic sulphides associated with Lead Sulphides, among them and more commonly pyrite. The same happens with Magnesium, usual in granitic rocks as well as in the polymetallic sulphides of the extracted seam. Potassium, as in the case of clay, is derived directly from the feldspars that conform the granite. The other elements are found in smaller proportion but must be studied later by leaching to check their retention in the ceramic matrix. Among these elements are Manganese, Titanium, Barium and Copper. The percentages are so small that they would not make extraction viable but if they can cause surface water and ground water contamination if they are in contact with it. It is worth noting the low percentage of Arsenic in the sample, being a very suitable value for its use in ceramics, since Arsenic is one of the most limited elements for manufacturing due to the contamination it can create in the leaching.

Evaluated the chemical composition of the initial materials, as well as the physical properties, it can be concluded that they are both compatible for use in the conformation of ceramic materials. However, special attention should be paid to a number of chemical elements present in the mining waste sample that may cause environmental problems if not retained in the ceramic matrix.

\subsection{Conformation of the Samples and Tests}

Here, we studied the characteristics of the clay and of the mining waste from Lead mine tailings, as well as evaluated for suitability for conformation of ceramic materials, we proceeded to the realization of the different groups of samples. The families carried out are those detailed in Table 1, being conforming and sintering according to the process detailed in the methodology. These samples of the different families were tested to determine the different physical properties detailed in this section. Firstly, the loss of weight and the linear shrinkage of the different families of samples conformed with clay and the mining waste are detailed in Figure 2.
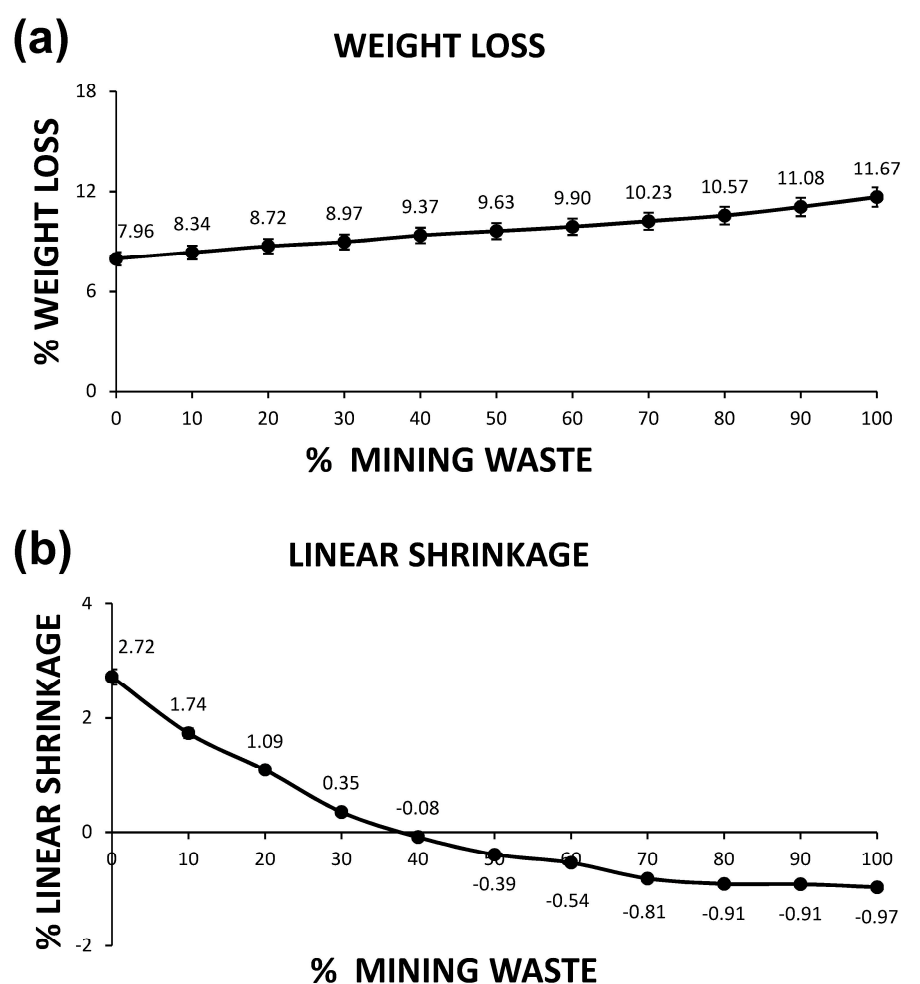

Figure 2. Physical properties of ceramic families with clay and mining waste after sintering (a) weight loss and (b) linear shrinkage. 
The weight loss of the different families of ceramic samples reflects a linear behaviour that increases as the percentage of mining waste increases. This is logical since it can be seen that the 0M10C family, composed only of clay, and the 10M0C family, composed only of mining waste, have similar weight losses to those obtained in the loss on ignition test for both materials - this coincidence derives that the temperature of this test and the sintering temperature are similar. Therefore, a linear increase in the percentage of mining waste leads to a linear increase in the loss of weight up to the maximum value. In short, the graph shows how the loss of weight between samples is quite similar, being greater the higher the percentage of mining waste. This fact will significantly affect the structure of the conformed ceramic with a higher percentage of mining residue, reflecting a higher percentage of pores.

In turn, the linear shrinkage of ceramic families decreases as the percentage of mining waste increases. A virtually zero linear shrinkage value is obtained for samples conformed with $40 \%$ mining residue and $60 \%$ clay. Higher values of mining residue in the samples cause to expand during the sintering process. This test, like the weight loss test, determines the subsequent physical and mechanical properties. A ceramic with a higher weight loss and a lower linear shrinkage after sintering produces a more open internal structure. This structure causes a lower density, a higher porosity and a lower resistance, however, these results must be studied and evaluated according to the limits established by the regulations.

The capillary water absorption and the cold water absorption of the different families of ceramics are detailed in Figure 3.
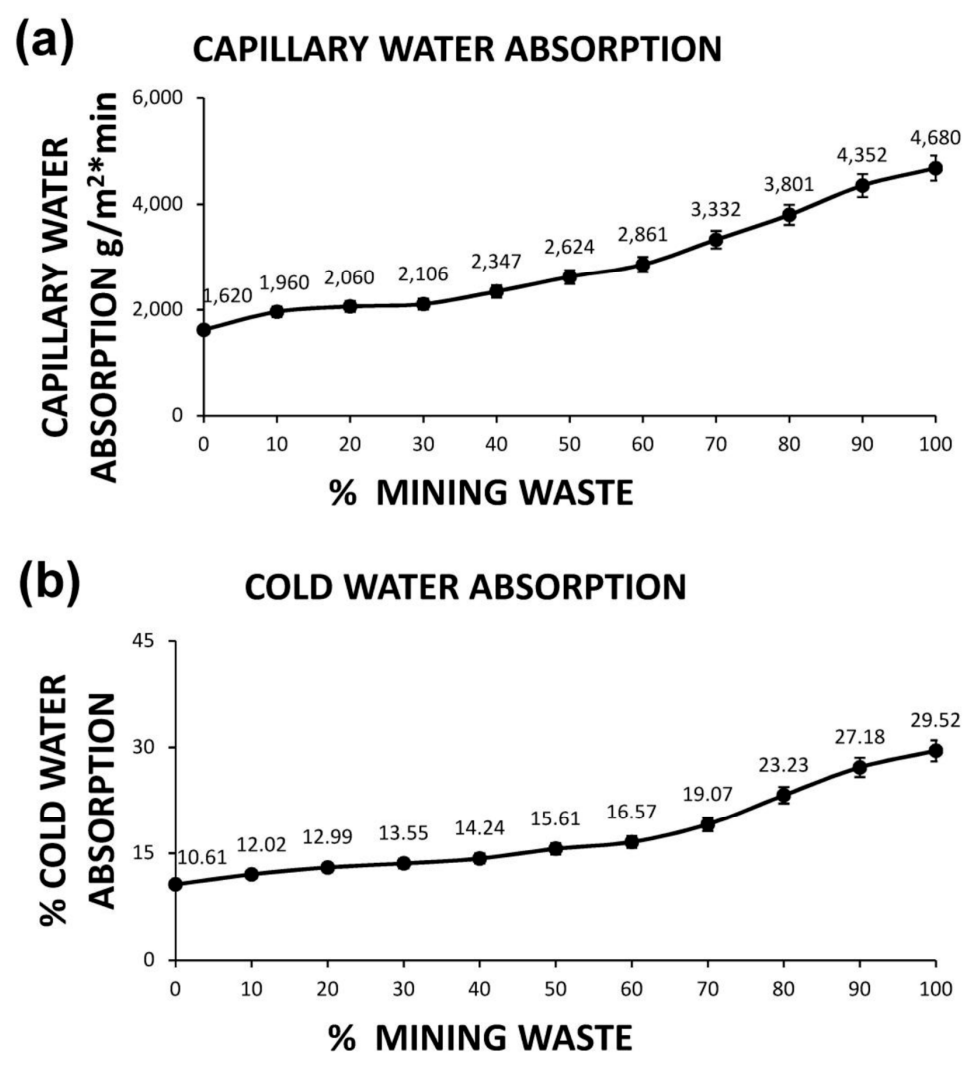

Figure 3. Physical properties of ceramic families with clay and mining residue after sintering (a) capillary water absorption and (b) cold water absorption.

The capillary water absorption of the different families of ceramics conformed clearly reflects the effect detailed by the previous properties. A higher percentage of mining waste creates a more open structure with a greater number of connected pores. It is therefore easy to see that the suction on this 
type of sample with a higher percentage of mining residue is higher. However, the standard sets a limit of $8500 \mathrm{~g} / \mathrm{m}^{2} \cdot \mathrm{min}^{-1}$, so all results are acceptable.

On the other hand, the cold water absorption increases at the same time as the percentage of mining waste in the ceramic increases. This fact is obvious for the comments made above, and will equally condition the properties of porosity, resistance and density. A greater absorption of cold water in the elements that are outdoors implies a greater weight of the ceramic elements with the contact of the water and, definitively, a greater weight in the structure that must support. However, the growth of this property is slow and in none of the cases are alarming values obtained. However, a different trend can be observed of the ceramics with a percentage higher than $60 \%$, reflecting a faster growth of cold water absorption that will be reflected later in other tests.

Figure 4 shows the results of the open porosity and bulk density tests of all the families of ceramics conformed.
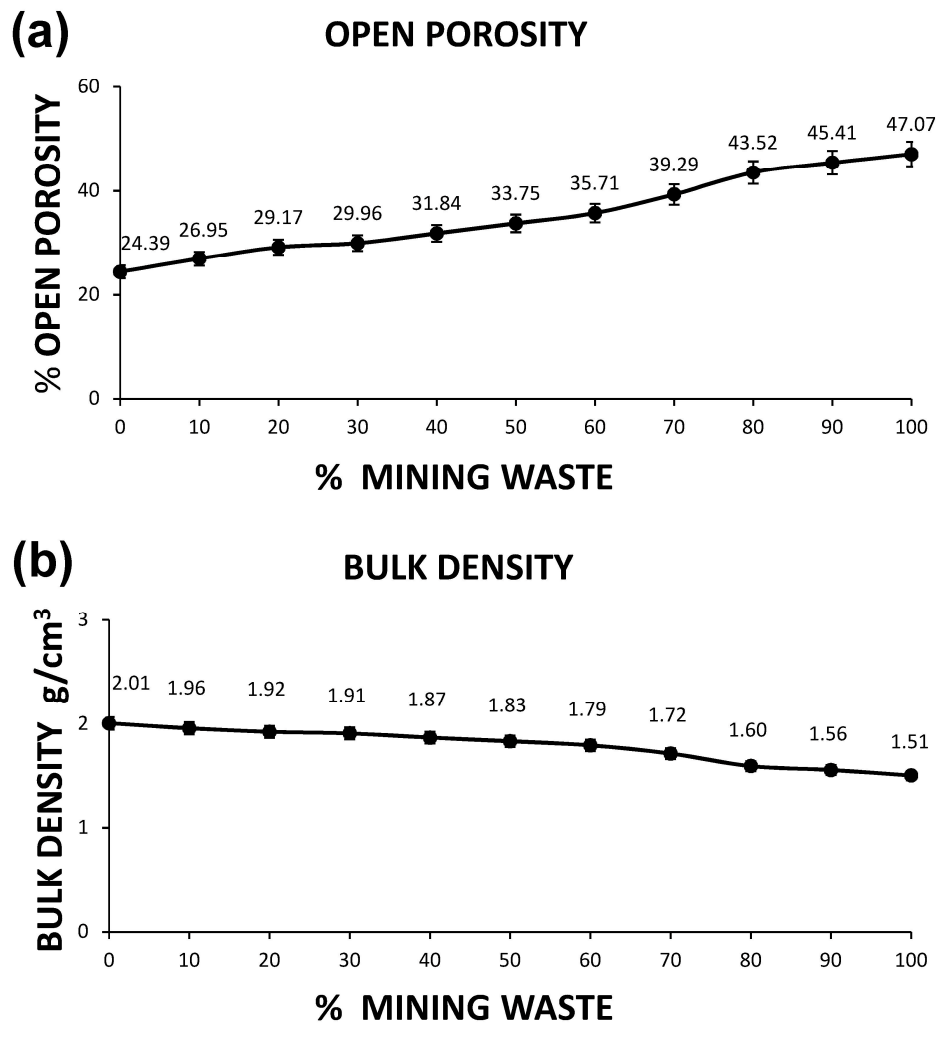

Figure 4. Physical properties of ceramic families with clay and mining residue after sintering (a) open porosity and (b) bulk density.

Figure 4 reflects the increase in open porosity with the increase in mining waste in ceramics. This was to be expected since families with higher percentages of mining waste previously reflected greater weight loss, less linear shrinkage, greater capillary water absorption and greater boiling water absorption. Therefore, the increase in porosity in ceramics with mining residue is clear and objective. However, a higher percentage of pores is not a problem, since if acceptable results are obtained by the regulations, an increase in the percentage of pores implies such desired properties in the Construction Sector as the decrease of thermal and acoustic conductivity. It should be noted that the material should not only be environmentally defined in its production, but also over its lifetime. A material with better thermal insulation directly causes a reduction in energy consumption for the climate equipment in the home, a very important factor to take into account.

On the other hand, and based on the results obtained in the previous physical properties analysis, it can be deduced, and it can be seen in Figure 4, that the density of the ceramic decreases while the 
percentage of the mining waste increases. A decrease in density in ceramic materials and under the same processing conditions directly conditions a lower compressive strength. However, if the limits set by the regulations are maintained, a lower density creates a lighter material. This lighter material reduces the weight that the structure must support, implying less consumption of structural materials.

Finally, Figure 5 shows the compressive strength of the different ceramics obtained and the deformation to breakage.
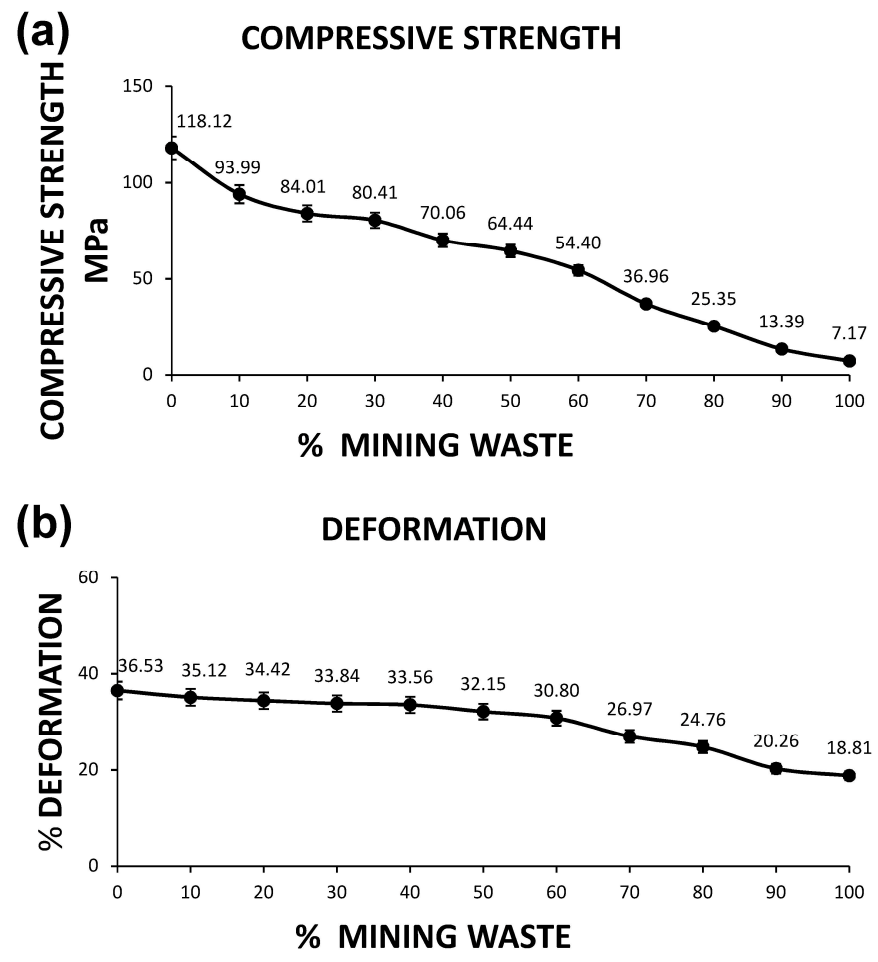

Figure 5. Physical properties of ceramic families with clay and mining residue after sintering (a) compressive strength and (b) deformation to breakage.

The compressive strength of the manufactured ceramics of the different families decreases when the percentage of mining waste increases. This is mainly due to the properties determined above, higher mass loss, lower linear shrinkage, and consequently lower density and higher porosity. The ceramic with mining residue has a more porous internal structure, with less capacity to resist the compressive loads. However, all the families conformed with a combination of clay and mining waste obtain acceptable results according to the regulations on in this respect, except the family 10M0C composed only of mining waste.

As the percentage of mining residue in the ceramic material increases, the deformation caused by the breaking strain decreases. Therefore, it can be concluded that the incorporation of the mining residue creates a more brittle and less ductile material, capable of resisting lower loads.

It is worth noting the increase in the slope of loss of resistance and decrease in deformation for percentages higher than $60 \%$ of mining waste. This phenomenon was already observed in the cold water absorption test and to a lesser or greater extent in all the physical properties results. This fact demonstrates the existence from $60 \%$ of mining waste in the ceramic of a substantial change of the obtained product, decreasing the characteristics resistant to a greater proportion. It is obvious to think therefore that, from this point, there exists a smaller percentage of clay capable of retaining and stabilizing the mining residue.

Finally, and as an essential characteristic within ceramics for bricks, Figure 6 reflects the color of all families of conformed ceramics from clay-only conformed ceramic (left) to mining residue-only 
conformed ceramic (right). The intermediate samples correspond to intermediate percentages of clay and mining waste combination.

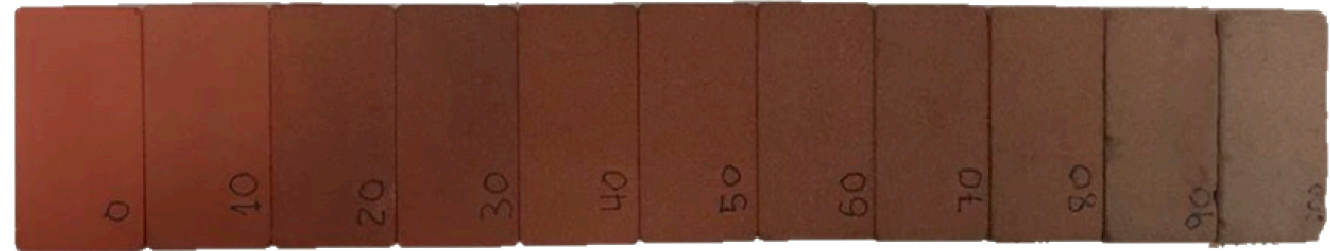

Figure 6. Image of the samples of the different families of ceramics conformed from clay and mining waste. From left to right, 0M10C, 1M9C, 2M8C, 3M7C, 4M6C, 5M5C, 6M4C, 7M3C, 8M2C, 9M1C and $10 \mathrm{M} 0 \mathrm{C}$.

As can be seen in Figure 6, the color varies progressively from reddish tones of the red sintered clay to brown tones of the sintered mining waste. The colour change is directly related to the chemical composition of the combination of clay and mining waste, since the conforming and the sintering process is the same. The colour is one more characteristic of the ceramic material, not limited by the regulations, but by the quality controls of the ceramic industry. A residue that combined with the clay creates a material with acceptable characteristics but produces rude changes in the colour of the product, may that not be accepted by the quality controls of the company. This is because there are margins in which the color of the ceramic can oscillate to maintain uniformity in production. Therefore, it can be affirmed that colour, although an important characteristic, is a quality that the market must accept and, therefore, in the scientific field it can only be faithfully recorded for subsequently reproduced by graphic means. With their detailed purpose, the colour coordinates of the different ceramic families are shown in Table 5 with the acceptable results in function on the primary colours.

Table 5. Red, Green and Blue coordinates of the color of the different families of samples conformed with clay and mining waste.

\begin{tabular}{ccccccccccc}
\hline Color & 0M10C & 1M9C & 2M8C & 3M7C & 4M6C & 5M5C & 6M4C & 7M3C & 8M2C & 9M2C \\
\hline Red & $310 \pm 7$ & $259 \pm 6$ & $247 \pm 7$ & $277 \pm 7$ & $291 \pm 6$ & $279 \pm 7$ & $284 \pm 8$ & $284 \pm 6$ & $271 \pm 8$ & $291 \pm 6$ \\
Green & $158 \pm 5$ & $153 \pm 4$ & $146 \pm 4$ & $157 \pm 4$ & $177 \pm 5$ & $172 \pm 3$ & $184 \pm 6$ & $191 \pm 4$ & $197 \pm 5$ & $220 \pm 6$ \\
Blue & $111 \pm 3$ & $114 \pm 3$ & $110 \pm 3$ & $116 \pm 3$ & $134 \pm 3$ & $131 \pm 3$ & $143 \pm 4$ & $149 \pm 3$ & $153 \pm 4$ & $177 \pm 4$ \\
\hline
\end{tabular}

The results of the physical and mechanical tests of the families of ceramic samples conformed with clay and mining residue have reflected a suitability of all families except the family conformed only with mining residue (10M0C). With these families of samples with acceptable results, the leachates of the contaminating elements we proceeded to analyze in greater proportion.

\subsection{Evaluation of the Leachates of the Ceramics}

Leachate from contaminants in mining waste from tailings from Lead mine washing plants should be analyzed for retention. The concentration of these elements in the leachate must also be evaluated to ensure that it is permitted by the regulations.

Based on the above, the analyses of the leachates of the different families of ceramics conformed, in comparison with the leachates of the unaltered mining waste, are detailed for the chemical elements Iron, Lead, Manganese, and Titanium in Figure 7.

Leachate from the heavy elements Iron, Lead, Manganese, and Titanium are drastically reduced when incorporated with clay in ceramic materials. This fact is easily observed in the graphs in Figure 7, which reflect a drastic decrease in the concentration of these elements in all families of ceramics conformed compared to the leachates of the unaltered sample represented in the first column of each graph (MW). The heavy metals are easily retained in the ceramic matrix and therefore avoid the existence of surface water or ground water contamination when in contact with the ceramic product. 

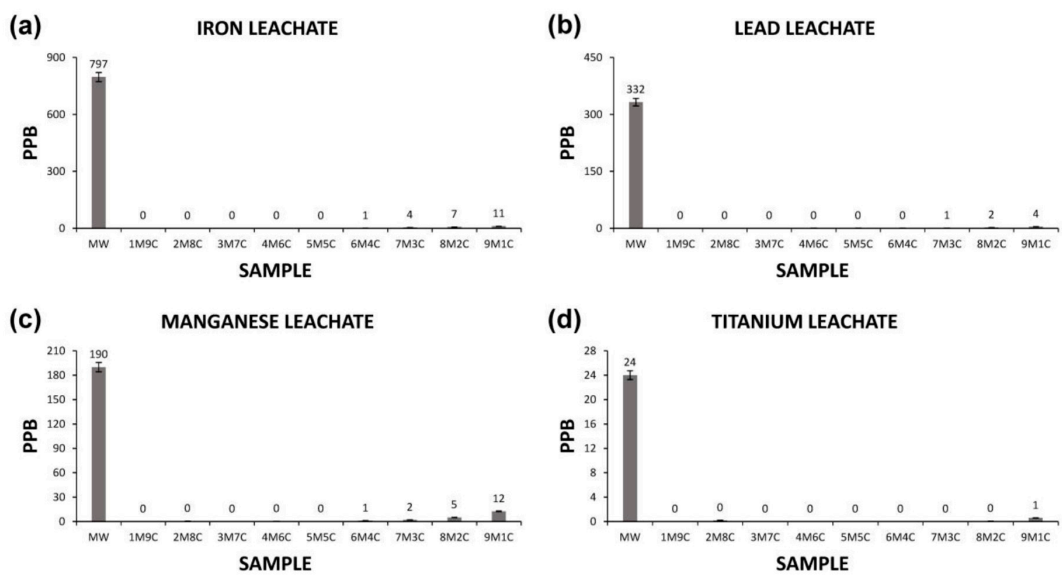

Figure 7. Leaching tests of chemical elements contaminating for the ceramic families with clay and mining residue and the unaltered mining residue sample. (a) Iron leachate, (b) Lead leachate, (c) Manganese leachate and (d) Titanium leachate.

On the other hand, the leachates of the different families of conformed ceramics and of the unaltered sample of the mining waste for the chemical elements Magnesium, Aluminium, Barium, and Copper are shown in Figure 8.

(a)

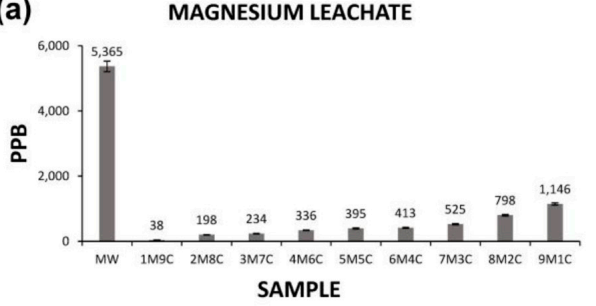

(c)

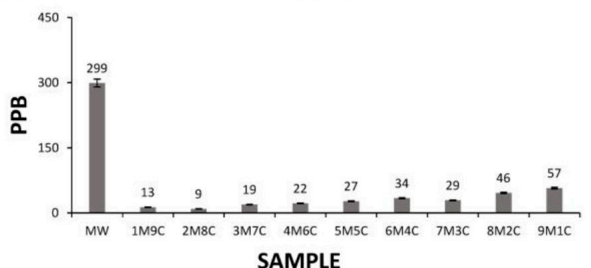

(b)

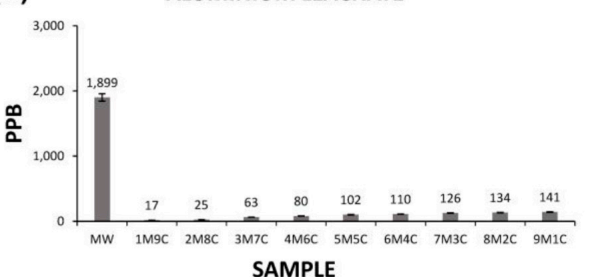

(d)

COPPER LEACHATE

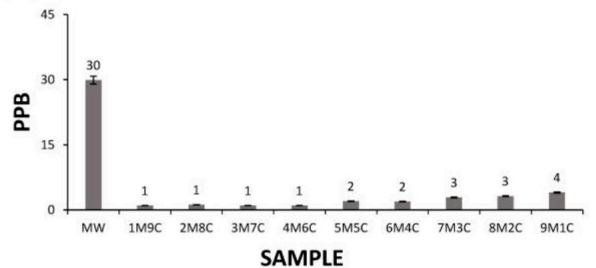

Figure 8. Leaching tests of chemical elements contaminating for the ceramic families with clay and mining residue and the unaltered mining residue sample. (a) Magnesium leachate, (b) Aluminium leachate, (c) Barium leachate and (d) Copper leachate.

The leachates of the elements Magnesium, Aluminium, and Barium, because they are light metals, and Copper, because it has a greater reactivity despite being a heavy metal, are not reduced in their totality, as in the previous case. However, it is easily observable how the concentration of the chemical elements detailed above is significantly reduced compared to the concentration in the leachates of the unaltered sample of the mining waste. Furthermore, the results obtained from the chemical elements detailed in the leachate of the ceramic families are acceptable by the regulations in this respect, and being therefore the families suitable for its manufacture and significantly reducing environmental pollution of the exposure of mining waste in large deposits to the elements.

Emphasis should be given to the importance of developing a material that not only incorporates a residue, but also inactivates it so that the associated environmental pollution that would occur if it were directly deposited does not occur. Therefore, the final objective of the incorporation of the waste and retention of contaminating elements is achieved. 


\section{Conclusions}

The tests detailed in the methodology provide a series of partial conclusions that will lead to the final conclusion, the viability of the development of ceramics with mining waste from tailings from Lead mine washing plants and the retention of those contaminating elements in greater proportion. It is important to highlight the importance of using a waste that is currently not used and that is causing significant environmental pollution due to its uncontrolled deposition, reducing the environmental impact, as well as creating a product with acceptable and sustainable characteristics.

The partial conclusions that can be extracted are:

- The density of the mining waste, as well as its particle size, makes it possible to mix it with the clay without any kind of pre-treatment, and thus to develop ceramic materials for bricks without homogenization problems.

- Elemental analysis, loss on ignition, and even X-ray fluorescence, showed a significant similarity between the mining waste and the clay. This fact facilitates the conformation of ceramics. This similarity is due to the rock from which the mining seam, granite, comes. This similarity is due to the rock from which the exploited seam comes by labourious mining the granite.

- There are a number of contaminants such as Iron, Lead, Manganese, Titanium, Magnesium, Aluminium, Barium, and Copper, which are found in greater proportion in mining waste and can cause significant environmental pollution. Therefore, it is necessary to evaluate leachates in ceramic products and confirm their retention in the ceramic matrix.

- Ceramics with mining waste develop a higher weight loss and a lower linear shrinkage. For this reason, they create a more porous internal structure, capable of obtaining a greater capillary water absorption, a greater cold water absorption, a greater porosity, and a lower density.

- The increase in porosity has a significant influence on the acquisition of probable thermal and acoustic insulation characteristics and is therefore an important fact to take into account.

- The decrease in density creates a lighter ceramic material that must support the structure, and therefore there is less use of structural elements.

- The compressive strength decreases with increasing percentage of mining waste and creates a more brittle material. However, all the families of ceramics with clay and mining waste have acceptable resistance values, except the family conformed only by mining waste.

- The colour of the samples varies progressively, without sudden changes and towards brown tones. The color was recorded for reproduction in graphic media.

- The heavy metals in the mining waste sample were retained in the ceramic matrix practically in their totality, as confirmed by the leachate test. Therefore, the environmental impact associated with the mining waste is reduced.

- The light metals and Copper were partially retained in the ceramic matrix, be necessary the use of higher sintering temperatures for their complete retention. However, the concentrations of these elements in the leachates studied for the ceramic families obtained are lower than the maximums set by the regulations.

On the basis of the detailed partial conclusions it can be stated that the conformation of ceramic materials for brick production from mining waste from Lead mine tailings washing plants is feasible. In addition, the ceramic matrix retains the existing contaminating elements in the waste and prevents environmental pollution.

Therefore, this study evaluates the use of a useless, polluting, and low-cost mining waste in ceramics with acceptable physical and mechanical results, thereby reducing its deposition in landfill, the contamination of ground and surface water, the extraction of new raw materials, and creating a sustainable product that retains the contaminating elements of the mining waste.

All the aspects mentioned above contribute to the development of a material framed inside of the new circular economy. Unlike the linear economy, in this research, a new life is given to the mining 
waste as a raw material for ceramic materials. Therefore, the closure of the material flows and the reduction of the environmental impact, associated to the extraction of new raw materials and the pollution caused by the waste in landfill, are achieved.

Author Contributions: Conceptualization, F.A.C.-I., F.J.I.-G., J.M.T.-S. and J.S.-M.; methodology, F.A.C.-I., F.J.I.-G., J.M.T.-S. and J.S.-M.; software, J.M.T.-S. and J.S.-M.; validation, F.A.C.-I. and F.J.I.-G.; formal analysis, F.A.C.-I. and F.J.I.-G.; investigation, J.M.T.-S. and J.S.-M.; resources, F.A.C.-I.; data curation, F.J.I.-G.; writing-original draft preparation, J.S.-M.; writing-review and editing, J.M.T.-S.; visualization, J.M.T.-S.; supervision, F.A.C.-I.; project administration, J.S.-M.; funding acquisition, F.A.C.-I. All authors have read and agreed to the published version of the manuscript.

Funding: This research received no external funding.

Acknowledgments: Technical and human support provided by CICT of Universidad de Jaén (UJA, MINECO, Junta de Andalucía, FEDER) is gratefully acknowledged.

Conflicts of Interest: The authors declare no conflict of interest.

\section{References}

1. Fuerstenau, M.; Jameson, G.; Yoon, R. Froth Flotation: A Century of Innovation; SME: Dearborn, MI, USA, 2007.

2. Peleka, E.N.; Gallios, G.P.; Matis, K.A. A perspective on flotation: A review. J. Chem. Technol. Biotechnol. 2018, 93, 615-623. [CrossRef]

3. Hansen, H.K.; Yianatos, J.B.; Ottosen, L.M. Speciation and leachability of copper in mine tailings from porphyry copper mining: Influence of particle size. Chemosphere 2005, 60, 1497-1503. [CrossRef]

4. De Xie, X.; Min, X.B.; Chai, L.Y.; Tang, C.J.; Liang, Y.J.; Li, M.; Ke, Y.; Chen, J.; Wang, Y. Quantitative evaluation of environmental risks of flotation tailings from hydrothermal sulfidation-flotation process. Environ. Sci. Pollut. Res. 2013, 20, 6050-6058. [CrossRef] [PubMed]

5. Navarro, M.C.; Pérez-Sirvent, C.; Martínez-Sánchez, M.J.; Vidal, J.; Tovar, P.J.; Bech, J. Abandoned mine sites as a source of contamination by heavy metals: A case study in a semi-arid zone. J. Geochem. Explor. 2008, 96, 183-193. [CrossRef]

6. Kefeni, K.K.; Msagati, T.A.M.; Mamba, B.B. Acid mine drainage: Prevention, treatment options, and resource recovery: A review. J. Clean. Prod. 2017, 151, 475-493. [CrossRef]

7. Mendez, M.O.; Maier, R.M. Phytoremediation of mine tailings in temperate and arid environments. Rev. Environ. Sci. Biotechnol. 2008, 7, 47-59. [CrossRef]

8. Li, M.S. Ecological restoration of mineland with particular reference to the metalliferous mine wasteland in China: A review of research and practice. Sci. Total Environ. 2006, 357, 38-53. [CrossRef]

9. Liu, J.; Shang, W.; Zhang, X.; Zhu, Y.; Yu, K. Mn accumulation and tolerance in Celosia argentea Linn.: A new Mn-hyperaccumulating plant species. J. Hazard. Mater. 2014, 267, 136-141. [CrossRef]

10. Liu, K.; Yu, F.; Chen, M.; Zhou, Z.; Chen, C.; Li, M.S.; Zhu, J. A newly found manganese hyperaccumulator-Polygonum lapathifolium Linn. Int. J. Phytoremediat. 2016, 18, 348-353. [CrossRef]

11. Vangronsveld, J.; Van Assche, F.; Clijsters, H. Reclamation of a bare industrial area contaminated by non-ferrous metals: In situ metal immobilization and revegetation. Environ. Pollut. 1995, 87, 51-59. [CrossRef]

12. Vangronsveld, J.; Sterckx, J.; Van Assche, F.; Clijsters, H. Rehabilitation studies on an old non-ferrous waste dumping ground: Effects of revegetation and metal immobilization by beringite. J. Geochem. Explor. 1995, 52, 221-229. [CrossRef]

13. Jonathan, M.P.; Jayaprakash, M.; Srinivasalu, S.; Roy, P.D.; Thangadurai, N.; Muthuraj, S.; Stephen-Pitchaimani, V. Evaluation of acid leachable trace metals in soils around a five centuries old mining district in hidalgo, central mexico. Water. Air. Soil Pollut. 2010, 205, 227-236. [CrossRef]

14. Kim, Y. Geochemical Behavior of Potentially Toxic Elements in Riverbank-Deposited Weathered Tailings and Their Environmental Effects: Weathering of Pyrite and Manganese Pyroxene. Minerals 2020, 10, 413. [CrossRef]

15. Mun, Y.; Strmić Palinkaš, S.; Forwick, M.; Junttila, J.; Pedersen, K.B.; Sternal, B.; Neufeld, K.; Tibljaš, D.; Kullerud, K. Stability of Cu-Sulfides in Submarine Tailing Disposals: A Case Study from Repparfjorden, Northern Norway. Minerals 2020, 10, 169. [CrossRef] 
16. Lao, C.; Zeledón, Z.; Gamisans, X.; Solé, M. Sorption of Cd(II) and Pb(II) from aqueous solutions by a low-rank coal (leonardite). Sep. Purif. Technol. 2005, 45, 79-85. [CrossRef]

17. Cortés, S.; Soto, E.E.; Ordóñez, J.I. Recovery of Copper from Leached Tailing Solutions by Biosorption. Minerals 2020, 10, 158. [CrossRef]

18. Nadeif, A.; Taha, Y.; Bouzahzah, H.; Hakkou, R.; Benzaazoua, M. Desulfurization of the Old Tailings at the Au-Ag-Cu Tiouit Mine (Anti-Atlas Morocco). Minerals 2019, 9, 401. [CrossRef]

19. Ahmadi, A.; Khezri, M.; Abdollahzadeh, A.A.; Askari, M. Bioleaching of copper, nickel and cobalt from the low grade sulfidic tailing of Golgohar Iron Mine, Iran. Hydrometallurgy 2015, 154, 1-8. [CrossRef]

20. Muravyov, M.I.; Fomchenko, N.V. Biohydrometallurgical treatment of old flotation tailings of sulfide ores containing non-nonferrous metals and gold. Miner. Eng. 2018, 122, 267-276. [CrossRef]

21. Liang, H.; Zhang, P.; Jin, Z.; DePaoli, D. Rare Earth and Phosphorus Leaching from a Flotation Tailings of Florida Phosphate Rock. Minerals 2018, 8, 416. [CrossRef]

22. Su, Z.; Chen, Q.; Zhang, Q.; Zhang, D. Recycling Lead-Zinc Tailings for Cemented Paste Backfill and Stabilisation of Excessive Metal. Minerals 2019, 9, 710. [CrossRef]

23. Tang, C.; Li, K.; Ni, W.; Fan, D. Recovering Iron from Iron Ore Tailings and Preparing Concrete Composite Admixtures. Minerals 2019, 9, 232. [CrossRef]

24. Ouyang, D.; Zhuo, Y.; Hu, L.; Zeng, Q.; Hu, Y.; He, Z. Research on the Adsorption Behavior of Heavy Metal Ions by Porous Material Prepared with Silicate Tailings. Minerals 2019, 9, 291. [CrossRef]

25. Almeida, M.I.; Dias, A.C.; Demertzi, M.; Arroja, L. Contribution to the development of product category rules for ceramic bricks. J. Clean. Prod. 2015, 92, 206-215. [CrossRef]

26. Rahhal, V.F.; Trezza, M.A.; Tironi, A.; Castellano, C.C.; Pavlíková, M.; Pokorný, J.; Irassar, E.F.; Jankovský, O.; Pavlík, Z. Complex Characterization and Behavior of Waste Fired Brick Powder-Portland Cement System. Materials 2019, 12, 1650. [CrossRef] [PubMed]

27. Kazmi, S.M.S.; Abbas, S.; Munir, M.J.; Khitab, A. Exploratory study on the effect of waste rice husk and sugarcane bagasse ashes in burnt clay bricks. J. Build. Eng. 2016, 7, 372-378. [CrossRef]

28. Oliveira, E.M.S.; Machado, S.Q.; Holanda, J.N.F. Caracterização de resíduo (lodo) proveniente de estação de tratamento de águas visando sua utilização em cerâmica vermelha. Cerâmica 2004, 50, 324-330. [CrossRef]

29. Youssef, N.F.; Abadir, M.F.; Shaterc, M.A. Utilization of Soda Glass (Cullet) in the Manufacture of Wall and Floor Tiles. J. Eur. Ceram. Soc. 1998, 18, 1721-1727. [CrossRef]

30. Pinatti, D.G.; Conte, R.A.; Borlini, M.C.; Santos, B.C.; Oliveira, I.; Vieira, C.M.F.; Monteiro, S.N. Incorporation of the ash from cellulignin into vitrified ceramic tiles. J. Eur. Ceram. Soc. 2006, 26, 305-310. [CrossRef]

31. Estévez, M.C.H.; Arrans, J.R.; Molina, J.D. Visita al Área Minera de Linares-Hidrogeología del Sector; Geological and Mining Institute: Madrid, Spain, 2002.

32. Ripoli Filho, F. A Utilização do Rejeito Industrial Cerâmico-Chamote-Como Fator de Qualidade na Fabricação de Elementos Cerâmicos: Um Estudo Experimental. Cerâmica 1997, 43, 133-139. [CrossRef]

33. Dondi, M.; Ercolani, G.; Guarini, G.; Raimondo, M. Orimulsion fly ash in clay bricks-Part 1: Composition and thermal behaviour of ash. J. Eur. Ceram. Soc. 2002, 22, 1729-1735. [CrossRef]

34. Menezes, R.R.; Ferreira, H.S.; de Neves, G.A.; Ferreira, H.C. Uso de rejeitos de granitos como matérias-primas cerâmicas. Cerâmica 2002, 48, 92-101. [CrossRef]

35. Bianchini, G.; Marrocchino, E.; Tassinari, R.; Vaccaro, C. Recycling of Construction and Demolition Waste Materials: A Chemical-Mineralogical Appraisal. In Proceedings of the Waste Management, Location of Meeting, Date of Meeting; Elsevier Ltd.: Amsterdam, The Netherlands, 2005; Volume 25, pp. 149-159.

36. Zegardło, B.; Brzyski, P.; Rymuza, K.; Bombik, A. Analysis of the Effects of Aggressive Environments Simulating Municipal Sewage on Recycled Concretes Based on Selected Ceramic Waste. Materials 2018, 11, 2565. [CrossRef] [PubMed]

37. Eliche-Quesada, D.; Martínez-García, C.; Martínez-Cartas, M.L.; Cotes-Palomino, M.T.; Pérez-Villarejo, L.; Cruz-Pérez, N.; Corpas-Iglesias, F.A. The use of different forms of waste in the manufacture of ceramic bricks. Appl. Clay Sci. 2011, 52, 270-276. [CrossRef]

38. Kazmi, S.M.S.; Abbas, S.; Saleem, M.A.; Munir, M.J.; Khitab, A. Manufacturing of sustainable clay bricks: Utilization of waste sugarcane bagasse and rice husk ashes. Constr. Build. Mater. 2016, 120, 29-41. [CrossRef] 
39. Subashi De Silva, G.H.M.J.; Mallwattha, M.P.D. Strength, durability, thermal and run-off properties of fired clay roof tiles incorporated with ceramic sludge. Constr. Build. Mater. 2018, 179, 390-399. [CrossRef]

40. Terrones-Saeta, J.M.; Suárez-Macías, J.; Iglesias-Godino, F.J.; Corpas-Iglesias, F.A. Study of the Incorporation of Biomass Bottom Ashes in Ceramic Materials for the Manufacture of Bricks and Evaluation of Their Leachates. Materials 2020, 13, 2099. [CrossRef]

(C) 2020 by the authors. Licensee MDPI, Basel, Switzerland. This article is an open access article distributed under the terms and conditions of the Creative Commons Attribution (CC BY) license (http://creativecommons.org/licenses/by/4.0/). 